DOI: $10.14451 / 2.140 .7$

\title{
ОБРАЩЕНИЕ ВЗЫСКАНИЯ НА КРИПТОАКТИВЫ В РОССИИ И ЗАРУБЕЖОМ: МИФ ИЛИ РЕАЛЬНОСТЬ
}

\author{
(C) 2020 Агеева Галина Евгеньевна \\ доцент кафедры гражданского и арбитражного процесса \\ Самарский государственный экономический университет, Россия, Самара \\ E-mail: galinaageevva@mail.ru \\ (c) 2020 Колга Ольга Викторовна \\ студент-магистрант юридического факультета \\ Самарский государственный экономический университет, Россия, Самара \\ E-mail: dgims1@mail.ru
}

Статья посвящена исследованию взглядов на природу «цифровой» валюты в России и за рубежом, анализу правовых проблем, связанных с появлением нового объекта исполнительного производства, пробелам действующего законодательства, а также поиску объективной необходимости обращения взыскания на криптоактивы. Авторами отмечены те обстоятельства, что в нашей стране криптовалюты пока не являются материальным благом, на которое возможно обратить взыскание. Несмотря на появление виртуальной валюты уже более десяти лет назад, а также несмотря на ее активную популярность не только в иностранных государствах, но и в нашей стране, ее правовое положение законодательным образом не определено. В процессе исследования проанализированы правовые позиции о цифровой валюте в разных странах. Акцентируется внимание на необходимости законодательного регулирования в Российской Федерации не только статуса криптовалюты, но и разработка механизма обращения на нее принудительного взыскания. Авторы приходят к выводу о том, что уже сегодня в стране назрела необходимость законотворческой инициативы, которая положит начало правового регулирования как цифровых процессов, так и результатов криптографической деятельности.

Ключевые слова: обращение взыскания, криптовалюта, криптоактив, электронный кошелек, исполнительное производство, судебный пристав исполнитель.

Мировое сообщество расходится во взглядах на сущность криптовалюты, однако нельзя не признать, что «цифровая» (виртуальная) валюта представляет собой некое имущество, выраженное в цифровом формате и используемое обладателем в качестве объекта инвестиций и иных целей [6].

Например, законодатель США понимает под криптовалютой - товар (актив), а Европейский суд принял постановление о том, что биткоин рассматривается, как некая валюта, которая не должна облагаться налогом на добавленную стоимость [14]. В Японии криптовалюта признается законодательством в качестве способа оплаты за товары и услуги и не облагается налогом на добавленную стоимость при обмене на обычную валюту [14].

Биткоин появился в 2009 году и до настоящего времени процветает, несмотря на пессимистические прогнозы, поскольку спрос рождает предложение. Любая криптовалюта, в том числе биткоин, имеет определенную ценность, которая выражена в эквивалентной денежной стоимости и обладает саморегулированием [16].

При рассмотрении актуальных проблемы, связанных с деятельностью судебных приставов исполнителей по обращению взыскания на имущество должника, невольно приходит на ум афоризм: «Если в нынешние времена вы не залезли в долги, вы, вероятно, занимаетесь чем-то противозаконным» [15].

Банкротство физических и юридических лиц в России является достаточно распространенной процедурой. Вопрос принудительного взыскания долгов с поиском новых источников удовлетворения требований кредиторов сегодня приобретает актуальную остроту. Новая зарождающаяся «цифровая экономика» требует от исполнительного производства поиска оригинальных механизмов и уникальных источников покрытия долгов должников перед кредиторами. Институт обращения взыскания на «цифро- 
вые» финансовые активы (криптоактивы) в настоящее время является достаточно молодым явлением за рубежом, а в нашей стране можно только наблюдать процесс его зарождения. Сегодня в российской действительности ни служба судебных приставов, ни судебная система не имеют законодательно отрегулированных механизмов, позволивших соответствовать экономической действительности.

К примеру, в Германии в 2018 году была произведена принудительная реализация с аукциона криптовалюты на сумму почти в $\$ 14$ млн., а Министерство юстиции США продало в октябре данного года «цифровой» конфискат в размере \$ 4.2 млн. [8].

В России «криптовалюта» на начало 2020 года является чем-то призрачным. Вроде бы существует, но законодатель так и не решил, как собственно должна произойти материализация данного явления в современной российской экономике.

В тексте проекта Федерального закона № 419059-7 «О цифровых финансовых активах и о внесении в отдельные законодательные акты Российской Федерации (о цифровых финансовых активах)» подготовленного ко второму чтению цифровые финансовые активы определяются как цифровые права, которые включают в себя обязательственные и иные права, в том числе и закрепленные в решении о выпуске цифровых финансовых активов. Различные процессы (выпуск, обращение и учет) подобных активов возможны только с помощью добавления записей в информационной системе на основе распределительного реестра [4]. Однако, что особенно интересно, вышеуказанный законопроект до настоящего времени не прошел второе чтение в Государственной Думе.

До настоящего времени, российский законодатель не смог для себя сформулировать, сущность таких понятий, как «цифровые деньги», «криптовалюта», и создать задатки адекватного регулирования «цифровой среды» на государственном уровне, предпочитая метод частичного игнорирования.

Рассмотрим, как дела обстоят на «цифровом» фронте в различных странах. Так в Китае в свете событий последних лет использование биткоина разрешено, но в любой момент ситуация может кардинально измениться, поскольку недавние жесткие директивы правительства заставили переместить бизнес некоторых криптовалютных компаний в Гонконг, где сохранилась лояльность к подобному бизнесу и снижено вмешательство государства [8].

Криптовалютные биржи сегодня процветают в Болгарии, Словении и Румынии, а Швейцария даже не пыталась создать специальную законодательную базу для регулирования криптоактивов, справедливо считая, что существующие нормативно-правовые акты успешно справляются с данным направлением.

Великобритания, в свою очередь создала благоприятные условия для развития криптовалютного бизнеса, а США, признав финансовыми учреждениями субъекты криптоэкономики (криптобиржи, криптообменники) обязали идентифицировать клиентов и представлять в контролирующий орган необходимую информацию. Подобные учреждения обязаны получать лицензию на занятие финансовой деятельностью в США [8].

Прямые запреты на использование в стране кибервалют установлен в таких странах, как Боливия, Эквадор, Таиланд, Вьетнам [8].

Оставаясь в стороне от «цифровых валют» и признания их существования в России, отечественный бюджет теряет несколько статей дохода, российские граждане - рабочие места, бизнес - новое направление развития.

В 2020 году наметилась любопытная тенденция в некоторых странах Запада, Японии, США: зарождаются идеи по созданию национальных криптовалют и активного их использования под присмотром государства. Идеи просто летают в воздухе. По мнению В.В.Григорьева, создание государственной цифровой валюты в России положительно отразится на экономике государства и позволит расширить инновационные сферы [9].

В заключении Комитета Государственной Думы по финансовому рынку о проекте Федерального закона № 419059-7 «О цифровых финансовых активах и о внесении в отдельные законодательные акты Российской Федерации (о цифровых финансовых активах)», содержится масса претензий по различным недочетам, которые до настоящего времени не устранены с марта 2019 [5].

Россия пребывает в состоянии ожидания, что не мешает ее гражданам заниматься инвестированием денежных средств в «цифровые» активы, криминальным структурам осваивать новые направления деятельности. 
В странах, активно внедряющих цифровые технологии, сформировалось устойчивое мнение об активном и главное своевременном участии законодателя в регулировании «цифровой среды», поскольку медлительность и косность создают «питательную» среду для развития «цифровой киберпреступности» [8].

Нельзя не согласиться с мнением А.А.Максурова о том, что признание криптовалюты государством непосредственно связано с уровнем его экономического развития, поскольку развитые страны выбирают направление политики по урегулированию и налогообложению «цифрового бизнеса» [11].

А.А.Максуров утверждает, что сегодня в России существует возможность использования криптовалюты в рамках действующего законодательства, как предмета сделки [11]. Гражданский кодекс Российской Федерации (далее ГК РФ) не содержит прямого указания о невозможности использования криптоактива в сделках [1].

Процесс совершенствования исполнительного производства предполагает наличие более широкие полномочий в вопросах определения размера имущества, которое необходимо изъять в счет погашения задолженности, что непосредственно окажет влияние на длительность процедуры взыскания.

Крипровалюта, как актив вполне может являться объектом исполнительного производства, в качестве иного имущества, а значит к нему возможно применение института обращения взыскания.

Исследования мнений нотариусов в 2018 году о включении криптовалюты в наследную массу показали полную неготовность рассмотрения данного актива, как имущества, которое гипотетически может включаться в закрытое завещание, и, следовательно, наследоваться. Замешательство нотариусов связано с отсутствием стоимостной оценки криптовалюты, разработанного механизма передачи прав по наследству и субъекта, который способен подтвердить наличие прав лица на криптоактив [11]. Прямого указания законодателя о запрете наследования нет, значит данная ситуация вполне вероятна.

Рассмотрим возможность внесения криптовалюты в уставный капитал общества с ограниченной ответственностью. Федеральная налоговая служба не установила запрета на внесение криптоактива в уставный капитал в качестве имущества. В 2019 году имел место факт вклю- чения биткоина в уставный капитал 000 «Артель» в размере 0,1 биткоина, что составило на момент внесения 60000 руб. Из всей ранее рассмотренной суммы 750 руб. вносилось для оплаты долей, а остальная сумма перечислялась на баланс предприятия. Проведение подобной операции включило в себя независимую оценку электронного кошелька экспертной группой, а также оформление акта приема-передачи логина и пароля от электронного кошелька с последующим заверкой комплекта документа у нотариуса [7]. Подобный прецедент говорит о появлении нового вида имущественных отношений, остро нуждающихся в государственном регулировании.

Статья 83 Семейного кодекса Российской Федерации (далее - СК РФ) предусматривает удержание алиментов из заработка и иного дохода, чем вполне может являться криптовалюта [2].

Итак, напрашивается вывод о том, что криптоактив становится активным участником гражданского оборота и, следовательно, объектом исполнительного производства. Криптовалюта является имуществом, которое с большой долей вероятности может включаться в конкурсную массу должника банкрота.

Проанализируем проблемы, которые сегодня назрели в судебной практике. В настоящее время приобрел актуальность вопрос о способах истребования информации о наличие криптоактива у должника-банкрота и включение его в конкурсную массу [12].

Отсутствие законодательного регулирования рассматриваемой сферы создает некоторые сложности, как для субъектов правоотношений, так и для правоприменителей. Мнение судий разделилось: одни считают, что криптовалюта не является объектом гражданских прав и не может включаться в конкурсную массу, так как находится вне правового поля, другие усматривают подобную возможность [13].

Так, в 2016 году в делах № A13-15648/2015 и № А13-3814/2016 судья Арбитражного суда Вологодской области Е.Н.Болдырева истребовала по запросу финансового управляющего у должников «справки об остатках электронных денежных средств» которые включали данные о криптовалюте (Bitcoin, Litecoin). Подобная практика имеется в АС Московской области, который затребовал по одному из дел доказательства, в частности информацию по международным системам расчета и средствам для ведения расчет- 
ных счетов, к которым одновременно отнес и WebMoney, Qiwi, ЯндексДеньги и BitCoin [12].

По мнению П.М. Морхата цифровую валюту, даже с учетом предложенного законодателем определения в законе о цифровых правах нельзя отнести к электронным денежным средствам. Однако суды сформировали на настоящем этапе свою положительную позицию о возможности удовлетворения требований кредиторов за счет включения криптоактивов в конкурсную массу должника [12].

Рассмотрим примеры из зарубежной практики. Например, Германия рассматривает криптовалюту, как некую часть имущества должника, включающуюся в конкурсную массу. Немецкое законодательство предусматривает добровольный порядок передачи ключей [12].

В 2018 году Верховный суд Южной Корей признал биткоин имуществом, в результате чего была применена конфискация [8].

А.Заточная отмечает, что развитие виртуальной валюты приводит к появлению новой доктрины «виртуальная собственность» [10], а появление нового вида собственности потребует от законодателя рождения механизма обращения.

Самой распространенной криптовалютой, являющейся предметом торгов и популярным объектом для инвестиций считается биткоин. На сегодняшний день его стоимость составляет 617817 рублей [17]. Для исполнительного производства - это значимый актив, позволяющий погасить единовременно существенные исковые требования кредиторов.

Все чаще в российских реалиях возникает неразрешимая дилемма: с одной стороны, должник, обладающий криптовалютой и имеющий желание предъявить данный вид актива, как собственное имущество и включить его в конкурсную массу, либо использовать в качестве источника для погашения требований кредиторов при исполнительном производстве, с другой, полное отсутствие механизма правовой реализации воли должника.

В соответствии со ст. 24 ГК РФ гражданин отвечает по своим обязательствам всем принадлежащим ему имуществом, за некоторым исключением, предусмотренным законодательством. Цифровые активы не входят в перечень имущества, на которое не может обращаться взыскание.

В отечественном законодательстве порядок обращения взыскания на имущество должни- ка определяет статья 69 Федерального закона «Об исполнительном производстве» [3].

Итак, рассмотрим вероятную модель обращения взыскания на «цифровые активы», очень актуальную в современных условиях для отечественной экономики.

Обращение взыскание на цифровые активы должно осуществляться в первую очередь при недостаточности денежных средств в рублях и иностранной валюте на основании решения суда. Инициатором процедуры может выступать в настоящее время как сам должник, так и заинтересованное лицо, которому стало известно о наличие подобного актива. Суду необходимо запрашивать информацию у должника о наличии, либо отсутствии криптоактивов при формировании конкурсной массы, а также при любом ином исполнительном производстве, поскольку данный источник наряду с денежной валютой обладает в данный момент значительной стоимостью. Информация о наличии «цифровых активов» у должника может предоставляться также и заинтересованной стороной.

Необходимо также закрепить обязанность для должника совершать по решению суда некоторые действия и предусмотреть ответственность за их несовершение:

1) должник в добровольном порядке предоставляет судебному приставу исполнителю пароль от криптокошелька, затем производится оценка стоимости криптовалюты (биткоина) на текущий момент и передается кредитору в натуральном выражении в погашение задолженности, при наличие его согласия, либо реализуется на аукционе конфиската (по опыту Германии);

2) должник через криптообменник самостоятельно производит обмен цифровой валюты на денежные единицы и перечисляет на счет судебных приставов исполнителей, с которого далее производится погашение требований кредиторов.

Оценка и обмен криптовалюты в рубли или иную иностранную валюту должна осуществляться финансовыми организациями, имеющими лицензию на совершение подобных действий и являющимися афилированными лицами коммерческих банков. Кроме того подобные организации можно обязать сообщать информацию о лицах проводящих криптографические операции, а также организовать регистрацию держателей криптовалюты в определенном реестре, что упростило бы исполнительное произ- 
водство.

Поскольку цифровые валюты имеют изменчивую природу, регулятивная деятельность государства может осуществляться мелкими шагами, но движение в данном направлении должно быть постоянным. Назрела необходимость описания законотворцами процесса обращения взыскания на цифровые активы, в том числе в рамках процедур о банкротстве.
Наше исследование показало, что необходимость обращения взыскания на криптоактивы для России приобретает реальные очертания. Напрашивается вывод о том, что уже сегодня в стране назрела необходимость законотворческой инициативы, которая положит начало правового регулирования как цифровых процессов так и результатов криптографической деятельности.

\section{Библиографический список}

1. Гражданский кодекс Российской Федерации (часть первая) от 30.11.1994 N 51-ФЗ (ред. от 16.12.2019). [Электронный ресурс]. URL: http://www.consultant.ru/cons/cgi/online.cgi?req=doc \&base=LAW \&n=340325 \&fld=134 \&dst=100131,0\&rnd=0.37.. (дата доступа 03.03.2020).

2. Семейный кодекс Российской Федерации от 29.12.1995 N 223-Ф3 (ред. от 02.12.2019) (ред. от 01.01.2020). [Электронный ресурс]. URL: http://www.consultant.ru/document/cons_doc_LAW_8982/ (дата доступа 29.01.2020).

3. Федеральный закон от 02.10.2007 N 229-ФЗ (ред. от 02.12.2019) «Об исполнительном производстве». [Электронный ресурс]. URL: http://www.consultant.ru/cons/cgi/online.cgi?req=doc \&base=LAW \&n=330824\&fld=134 \&dst=100512,0\&rnd=0.98494124 (дата доступа 03.03.2020).

4. Проект Федерального закона N 419059-7 «О цифровых финансовых активах и о внесении изменений в отдельные законодательные акты Российской Федерации (о цифровых финансовых активах)» (текст ко второму чтению). [Электронный ресурс]. URL: https: // www.consultant.ru/law/hotdocs/57223.html/ (дата доступа 29.01.2020).

5. Система обеспечения законодательной деятельности. Законопроект № 419059-7 [Электронный ресурс]. URL: https://sozd.duma.gov.ru/bill/419059-7.

6. Агеева Г.Е., Колга О.В. Криптовалюта как объект взыскания в исполнительном производстве // Институциональная трансформация правовой среды в условиях цифровизации экономики [Текст]: материалы VII Междунар. науч.-инновац. форума «Как выжить в цифровую эпоху?», 22-26 апр. 2019 г. / [редкол.: С. П. Бортников (отв. ред.) и др.]. - Ч. 1. - Самара: Изд-во Самар. гос. экон. ун-та, 2019. - 380 с. С. 14-20. ISBN 978-5-94622-934-0

7. Ваганов А. Биткоин зачли по уставу // Комерсантъ, 2019. № 216 (6696). [Электронный pecypc]. URL: https:// www.kommersant.ru/doc/4170151(дата обращения: 02.02.2020).

8. В Великобритании состоится первый аукцион по продаже криптовалюты [Электронный pecypc]. URL: http// www.rucoin.net/v-velikobritanii-sostoitsya-pervyiy-auktsion-po-prodazhe-kriptovalyutyi/ (дата обращения 29.01.2020).

9. Григорьев Владимир Викторович Национальная цифровая валюта как фактор оживления экономики России // Экономика. Налоги. Право. 2019. № 1. [Электронный ресурс]. URL: https://cyberleninka.ru/article/n/ natsionalnaya-tsifrovaya-valyuta-kak-faktor-ozhivleniya-ekonomiki-rossii (дата обращения: 31.01.2020).

10. Заточная А.Д. Правовые аспекты использования цифровых валют: мировой опыт // Евразийская адвокатура. 2017. № 6 (31). [Электронный ресурс]. URL: https://cyberleninka.ru/article/n/pravovye-aspektyispolzovaniya-tsifrovyh-valyut-mirovoy-оруt (дата обращения: 31.01.2020).

11. Максуров А.А. Криптовалюта в гражданском, семейном и трудовом праве России // Имущественные отношения в РФ. 2018. № 8 (203). [Электронный ресурс]. URL: https://cyberleninka.ru/article/n/kriptovalyuta-vgrazhdanskom-semeynom-i-trudovom-prave-rossii (дата обращения: 31.01.2020).

12. Морхат П. М. Криптовалюта в конкурсной массе должника-банкрота. Правовая неопределенность // Закон и право. 2019. № 4. [Электронный ресурс]. URL: https://cyberleninka.ru/article/n/kriptovalyuta-v-konkursnoymasse-dolzhnika-bankrota-pravovaya-neopredelennost (дата обращения: 31.01.2020).

13. Урошлева А. Объекты на цифровых носителях, цифровые права и деньги: тенденции правовой теории и практики. [Электронный ресурс] URL: https://www.garant.ru/article/1220358/(дата доступа 29.01.2020).

14. Фиалковская И.Д. Виртуальная валюта: проблемы государственного регулирования и налогоображения (зарубежный опыт) // Вестник ННГУ. 2019. № 2. [Электронный pecypc]. URL: https://cyberleninka.ru/article/n/ virtualnaya-valyuta-problemy-gosudarstvennogo-regulirovaniya-i-nalogooblozheniya-zarubezhnyy-opyt (дата обращения: 31.01.2020). 
15. Цитаты и афоризмы. [Электронный ресурс]. URL: https://parfumclub.org/other/citaty-pro-dolzhnikov.html (дата доступа 19.02.2019 г.).

16. Шнейдерова Д.И. Противодействие использованию цифровой валюты в процессе совершения хищений // Академическая мысль. 2019. № 1 (6). [Электронный ресурс]. URL: https://cyberleninka.ru/article/n/ protivodeystvie-ispolzovaniyu-tsifrovoy-valyuty-v-protsesse-soversheniya-hischeniy (дата обращения: 31.01.2020).

17. Мониторинг обменников BestChange.ru. [Электронный ресурc]. URL: // www.bestchange.ru/?utm source=yandex \&utm_medium $=$ cpc \&utm_campaign $=37626639 \& u$ tm_term $=\%$ D0\%BA\%D1\%83\%D0\%BF\%D0\% B8\%D1\%82\%D1\%8C\%20\%D0\%BA\%D1\%80\%D0\%B8\%D0\%BF\%D1\%82\%D0\%BE\%D0\%B2\%D0\%D1\%83\&utm_ content=6451993970 (дата доступа 22.02.2020). 